\title{
When infection prevention enters the temple: Intergenerational social distancing and COVID-19
}

\author{
David M. Hartley PhD, MPH ${ }^{1,2}$, Heather Schacht Reisinger PhD ${ }^{3,4}$ and Eli N. Perencevich MD, MS 3,4 (D) \\ ${ }^{1}$ Cincinnati Children's Hospital, James M. Anderson Center for Health Systems Excellence, Cincinnati, Ohio, ${ }^{2}$ Department of Pediatrics, University of Cincinnati, \\ College of Medicine, Cincinnati, Ohio, ${ }^{3}$ Center for Access \& Delivery Research and Evaluation, lowa City Veterans' Affairs Health Care System, lowa City, lowa and \\ ${ }^{4}$ Department of Internal Medicine, Carver College of Medicine, University of lowa, lowa City, lowa
}

To the Editor-The recent emergence of SARS-CoV-2 and the pandemic of associated COVID-19 disease poses significant though incompletely determined threats to human health globally. Although uncertainties predominate the epidemiology of this new virus, ${ }^{1}$ several observations are relevant for policy making at this stage of the pandemic:

- Asymptomatic transmission. Increasing evidence suggests that the time from infection to infectiousness (the latency period) is less than the time to symptoms (the incubation period). Thus, people may inadvertently infect others before realizing they are infected because they are not yet experiencing symptoms. Asymptotic cases may be particularly common in children and young adults.

- Disease severity and risk of death. The crude case fatality ratio is estimated to be significantly higher than that for seasonal influenza, ${ }^{3}$ and it is dramatically higher in the aged and those with underlying comorbid conditions (especially cardiovascular disease, pulmonary disease, and diabetes) regardless of age. ${ }^{3}$ Persons in at-risk strata form a significant fraction of the world population.

- Lack of options for control. No vaccine or effective antiviral drug is likely to be widely available for months or longer. ${ }^{4}$

Combined with lack of widespread diagnostic testing, these factors have produced one crucial implication for public health: Without intervention, people in the high-risk strata will be exposed by those around them who do not realize they are infectious. This situation is particularly acute with intergenerational mixing among the asymptomatic, in which infectious youths might intermingle with the high-risk elderly.

Given the lack of a vaccine and drugs for treatment, how do we minimize the community risk of becoming infected? Nonpharmaceutical interventions (eg, broad-scale social distancing, including school closures, working from home, and limiting large-sized gatherings) are needed to minimize transmission. Analyses are demonstrating the theoretical and historical impacts of such measures in scenarios similar to what we face now. ${ }^{5}$

Importantly, large intergenerational gatherings, including religious services, have amplified the spread of SARS-CoV-2 in South Korea, Malaysia, and other countries. ${ }^{6-9}$ Traditions such as

\footnotetext{
Author for correspondence: Eli N. Perencevich, E-mail: eli-perencevich@uiowa.edu Cite this article: Hartley DM, Reisinger HS, and Perencevich EN. (2020). When infection prevention enters the temple: Intergenerational social distancing and COVID19. Infection Control \& Hospital Epidemiology, 41: 868-869, https://doi.org/10.1017/ ice. 2020.100
}

handshaking, embracing, touching the Torah, use of prayer mats and passing offering plates, for example, could place persons at risk for acquiring SARS-CoV-2 in close proximity to those who may be asymptomatically or inapparently infectious. Some religious communities have recently offered guidance to congregations aimed at minimizing risk of transmission, including suspending in-person services for weeks.

Such policies must be implemented immediately. Waiting until community transmission is detected-according to any definition-is too late, ${ }^{10}$ even if surveillance systems capable of detecting transmission with any degree of sensitivity or timeliness existed, which they do not. The difference in latency versus incubation period in this novel pathogen obviates the appropriateness of such a policy. The time for social distancing is now.

Acknowledgments. The views expressed in this article are those of the authors and do not necessarily reflect the position or policy of the Department of Veterans' Affairs or the US government.

Financial support. No financial support was provided relevant to this article.

Conflicts of interest. All authors report no conflicts of interest relevant to this article.

\section{References}

1. Anderson RM, Heesterbeek H, Klinkenberg D, Hollingsworth TD. How will country-based mitigation measures influence the course of the COVID-19 epidemic? Lancet 2020;395:931-934.

2. Coronavirus disease (COVID-2019) situation report-30. World Health Organization website. https://www.who.int/docs/default-source/coronaviruse/ situation-reports/20200219-sitrep-30-covid-19.pdf?sfvrsn=3346b04f_2. Published February 19, 2020. Accessed April 3, 2020.

3. People at risk for serious illness from COVID-19. Centers for Disease Control and Prevention website. https://www.cdc.gov/coronavirus/2019ncov/specific-groups/high-risk-complications.html. Published March 15, 2020. Accessed April 3, 2020.

4. Fauci AS, Lane HC, Redfield RR. COVID-19-navigating the uncharted. N Engl J Med 2020;382:1268-1269.

5. Hatchett RJ, Mecher CE, Lipsitch M. Public health interventions and epidemic intensity during the 1918 influenza pandemic. Proc Natl Acad Sci U S A 2007;104:7582-7587.

6. Rashid R. Being called a cult is one thing, being blamed for an epidemic is quite another. New York Times website. https://www.nytimes.com/2020/03/ 09/opinion/coronavirus-south-korea-church.html. Published March 9, 2020. Accessed April 3, 2020.

7. Malaysia reports 41 new cases of COVID-19, most linked to religious event. Channel News Asia website. https://www.channelnewsasia.com/news/asia/ coronavirus-malaysia-190-new-cases-mosque-religious-event-12539994. Published March 15, 2020. Accessed April 3, 2020. 
8. Nine new cases of COVID-19 infection confirmed. Singapore Ministry of Health website. https://www.moh.gov.sg/news-highlights/details/ninenew-cases-of-covid-19-infection-confirmed. Published March 12, 2020. Accessed April 3, 2020.

9. Boorstein M. The Georgetown church quarantined by DC's coronavirus outbreak. The Washington Post website. https://www.washingtonpost. com/religion/2020/03/09/dc-priest-with-coronavirus-leads-prominenthistoric-episcopal-parish/. Published March 9, 2020. Accessed April 3, 2020.

10. Remuzzi A, Remuzzi G. COVID-19 and Italy: what next? The Lancet website. https://www.thelancet.com/journals/lancet/article/PIIS0140-6736(20) 30627-9/fulltext. Published March 13, 2020. Accessed April 3, 2020.

\title{
Artificial intelligence plays an important role in containing public health emergencies
}

\author{
Ningning Tang MD, Guangyi Huang MD, Min Li MD and Fan Xu MD (1) \\ Department of Ophthalmology, People's Hospital of Guangxi Zhuang Autonomous Region, Nanning, Guangxi, China
}

To the Editor-Despite measures taken by the Chinese government to contain coronavirus disease 2019 (COVID-19), its transmission has yet to be halted. Instead, the SARS-Cov-2 virus has demonstrated international seeding leading to a global outbreak. ${ }^{1}$ Although many technical gaps and uncertainties remain in the epidemic management techniques, artificial intelligence (AI) offers the potential for concerned parties to fill these gaps using big data.

Currently, thanks to the support of the Ministry of Industry and Information Technology of China, ${ }^{2}$ research institutions and enterprises across China are actively optimizing AI algorithms and computing power for epidemic control. For example, an automated whole-genome sequencing and analysis platform has been established to promote rapid and accurate virus detection. ${ }^{3}$ Additionally, protein screening, as well as new drugs and vaccine development, have been accelerated thanks to the use of AI. ${ }^{4}$ By applying image-processing algorithms, chest computed tomographic images can be intelligently diagnosed and quantitatively evaluated, and the severity of various types of pneumonia (ranging from local lesions and diffuse lesions to whole-lung involvement) are automatically graded. ${ }^{5}$ Case assessments for COVID-19 using AI systems show acceptable accuracy with high efficiency. ${ }^{5}$ Phonetic interface systems and speech-recognizing robots are frequently employed in healthcare settings to provide intelligent guidance and triage services. ${ }^{6}$ In some communities and public places, these systems can replace healthcare workers in performing some routine tasks, such as temperature measurement, that can be done automatically and accurately through a combination of deep learning, image recognition technology, and infrared imaging sensors. ${ }^{7}$ Smart-dial service can be used employed to conduct phonetic verification with preset conversation content (eg, health status, travel, and contact history), so that residents' health conditions and population mobility can be efficiently investigated. ${ }^{8}$ Facial recognition technology is used to track behavior via real-time processing of video data of close contacts of confirmed and/ or suspected cases. ${ }^{9}$ All in all, the application of AI technology has opened up opportunities for the integration and utilization

Author for correspondence: Fan Xu, E-mail: oph_fan@163.com

Cite this article: Tang N, et al. (2020). Artificial intelligence plays an important role in containing public health emergencies. Infection Control \& Hospital Epidemiology, 41: 869-870, https://doi.org/10.1017/ice.2020.103 of big data across the whole of Chinese society, providing a wealth of information for hospital management, community supervision, and government policy formulation.

Efforts made by a single country remain insufficient. Although the world is currently facing the COVID-19 epidemic, other events, such as a natural disaster followed by a pandemic, might occur in the future as well. In such an event, worldwide data sharing and technology communication will be required to both create and launch a global, public health emergency response plan and to effectively contain the public health emergency. We hope that an open AI-based platform, with epidemiological database integration and comprehensive coverage worldwide, will be established to maximize the benefits of AI and big data. In this way, the nations of the world can cooperate more closely to effectively respond to the common crises that face all of mankind.

Acknowledgments.

Financial support. No financial support was provided relevant to this article.

Conflicts of interest. All authors declare no conflict of interest relevant to this study.

\section{References}

1. Coronavirus disease 2019 (COVID-19) situation report-36. World Health Organization website. https://www.who.int/docs/default-source/coronaviruse/ situation-reports/20200225-sitrep-36-covid-19.pdf?sfvrsn=2791b4e0_2. Published 2020. Accessed February 25, 2020.

2. The proposal of leveraging the power of artificial intelligence to fight against COVID-19. Ministry of Industry and Information Technology of the People's Republic of China website. http://www.miit.gov.cn/n1146290/ n1146402/n1146440/c7664158/content.html. Published 2020. Accessed Feb 4, 2020.

3. Zhejiang Province CDC launches automated whole-genome sequencing and analysis platform. China News website. http://www.chinanews.com/gn/ 2020/02-01/9075431.shtml. Published 2020. Accessed Feb 1, 2020.

4. Zhongshan Nan's team and Alibaba Cloud have reached a cooperation to develop new drugs and vaccine for COVID-19. Xinhuanet website. http:// www.xinhuanet.com/tech/2020-02/14/c_1125574885.htm. Published 2020. Accessed February 14, 2020.

5. Shanghai Public Health Center launched intelligent evaluation system for COVID-19. Netease website. https://3g.163.com/tech/article/F4KKGF6H000 97U80.html. Published 2020. Accessed February 5, 2020. 